\title{
Submarine Resistance Force Characteristics Determination After Modification of Depth Rudder System
}

\author{
Radosław Kiciński ${ }^{1}$, Wojciech Jurczak ${ }^{*}$ \\ 1 Polish Naval Academy, Mechanical and Electrical Engineering Faculty, Gdynia, Poland \\ *Corresponding author's email:w.jurczak@amw.gdynia.pl
}

\begin{abstract}
A submarine, as a technical object, has many systems which are necessary for operation. In addition to the weapon systems, there are many systems required for the safe operation under the water. The submarine steering system is one of them. The article presents the principle of operation and the modification concept of the stern rudders of the project 207 (Kobben class) submarine. On the basis of measurements, the resistance force characteristics were determined. A calculation model was proposed using CFD (Computational Fluid Dynamics) and CAE (Computer Aided Engineering) techniques to determine the resistance force characteristics during the design stage. Then, the measured resistance force characteristics were used to verify the calculation model. Using the proposed method, the resistance force characteristics for an existing submarine were determined, and then its modification was proposed. The simulation results for the modified rudder design allowed determining the reduction of the ship resistance force for the new solution. Lower resistance force means lower demand for electrical power in the engine room, which consequently affects the operational safety by increasing maneuverability and improving the immersion curve. The proposed modification enables to reduce the power consumption by about $8 \mathrm{~kW}$ and reduced the resistance force by $2 \%$, which increased the ship's autonomy.
\end{abstract}

Keywords: submarine, finite element method, computational fluid dynamics, resistance force, operational submarine safety

\section{INTRODUCTION}

A submarine, as a technical object, has many systems necessary for operation. In addition to the weapon systems, the thoroughly discussed in other papers, there are many systems the principle of operation of which is not common knowledge. Sailing under water of such objects is not a natural state and requires the knowledge of specific phenomena and the operation of systems necessary to maintain the submarine at a given depth. In order to do so it is necessary to use following systems: propulsion (ship speed), hydraulic with rudders, ship balancing system, bilge ballast system, etc. The ship's balancing is carried out all the time due to the use of armament, fuel consumption and others.

Nowadays, two Kobben-type submarines are still in operation of the Polish Navy, which due to the year of construction are intended for decommissioning. The consequence of this is declassification of the technical documentation of those ships, which allows the disclosure of certain operational parameters. This allows, among other things, to determine the approximate resistance force characteristics. The knowledge of this characteristic allows the use of modern computer techniques to, for example, modify the steering system. The idea of the rudder system modification is not new and was described in the literature [1-3]. Rudders can be modified to optimize them or to change the way they work. It also affects the total resistance force of the ship's hull. The methods described in the literature mainly present the pressure and flow velocities around the steering gear. It should be checked how the modifications to the steering system affect the entire ship. 
The article presents the concept of changing the steering system of a submarine, which has a direct impact on her resistance force characteristics. On the basis of own research, the resistance force characteristics of a Kobben class submarine (project 207) were determined. Using declassified technical data, a CAE (Computer Aided Engineering) model of the existing submarine was made. Then, it was proposed to modify the model by replacing the classic form rudder with an $\mathrm{X}$-form rudder.

Using the measuring devices installed on the ship, the current flowing through the armatures of the main electric motor and the battery voltage were measured. Then, the ship's power was calculated at a given sailing speed. On the basis of the power, the ship's resistance force was determined. The mentioned power is necessary to compensate for the total hull resistance force taking into account the efficiency and resistance force of the propeller, as well as the resistance force in the shaft line bearings and other accompanying phenomena.

\section{RESISTANCE FORCE OF SUBMARINES}

The first stages of ships or warships designing are: analysis of similar units, followed by the preparation of appropriate resistance force characteristics to determine the necessary engine room power. The next stage is the selection of propellers and the propulsion system. Unfortunately, the current state of knowledge and numerical methods, as well as the available computing power of computers, did not allow determining the resistance force of the unarmed ship's hull during its design with satisfactory accuracy. Therefore, the most accurate methods currently used to determine the hull resistance force are model tests.

There are also approximate analytical methods. According to the theory, the ship's resistance force can be represented by the formula [4-6]:

$$
R=c_{f} \cdot \frac{\rho v^{2}}{2} \cdot \Omega
$$

where: $R$ - ship resistance force, $\mathrm{N}$;

$c_{f}-$ total resistance force coefficient;

$\rho$ - water density, $\mathrm{kg} / \mathrm{m}^{3}$ (assumed

$\rho=1025 \mathrm{~kg} / \mathrm{m}^{3}$ );

$v$ - ship speed, $\mathrm{m} / \mathrm{s},(1 \mathrm{kt}=0,5145 \mathrm{~m} / \mathrm{s})$;

$\Omega$-wetted surface of the hull, $\mathrm{m}^{2}$.
Knowing the resistance force of the hull, it is possible to calculate the towing power:

$$
P_{h}=R \cdot v
$$

The hull resistance force in water can be divided into the resistance force of the unarmed hull, air resistance force and resistance force of the equipment elements, the modeling of which in calculations or in model tests is troublesome or even impossible. These elements include, among others, propeller shafts, sonar covers, Kort nozzles, etc. The total resistance force $R$ of the water structure of a ship's construction is equal to the sum of the following resistances:

$$
R=R_{t}+R_{\text {air }}+R_{\text {prot }}+R_{\text {wave }}
$$

where: $R_{t}$ - friction resistance force;

$R_{\text {air }}-$ air resistance force;

$R_{p r o}$ - resistance force of protruding parts;

$R_{\text {wave }}^{\text {pro }}$-wave resistance force.

The ship in motion is subjected to the intermolecular forces of the water that surrounds her. This force it is a friction resistance force. In order to determine the coefficient of friction of the ship, the Reynolds number should be defined. This number allows to estimate the ratio of the active forces to the reactive forces (inertia forces) associated with the internal friction in a fluid manifested in the form of viscosity occurring during the fluid movement. The Reynolds number is determined in the form $[5,7]$ :

$$
R_{\mathrm{n}}=\frac{v \cdot L}{v}
$$

where: $v$ - flow speed, $\mathrm{m} / \mathrm{s}$;

$$
\begin{aligned}
& L \text { - length, } \mathrm{m} ; \\
& v \text { - kinematic viscosity coefficient, } \mathrm{m}^{2} / \mathrm{s}
\end{aligned}
$$

On the basis of the model research, a number of formulas were developed to determine the friction resistance coefficient of a flat plate $c_{f}$ as a function of the Reynolds number $R_{n}[6,8]$ :

- Prandtl - Schlichting formula:

$$
c_{f 0}=0,455\left[\log _{10} \cdot R_{\mathrm{n}}\right]^{-2,58}
$$

- ITTC formula:

$$
c_{f 0}=\frac{0,075}{\left(\log R_{\mathrm{n}}-2\right)^{2}}
$$

The next step necessary to determine the resistance force characteristics is to specify the wetted hull surface. It is a surface that is 
directly immersed in a liquid and upon which the friction forces act.

In the case of a submarine, the surface area can be calculated as a cylinder area with a diameter and length equal to the diameter and length of the submarine. The wetted surface of a fully immersed hull calculated with the cylinder method was equal to $\Omega=732.22 \mathrm{~m}^{2}$. In addition, the computer techniques were used to calculate the wetted area of the entire hull. On the basis of the model created in the CAD program shown in Figure 1, the hull surface was calculated as $\Omega=731.26 \mathrm{~m}^{2}$ for the existing model and $\Omega=725.35 \mathrm{~m}^{2}$ after rudder modification.

\section{Resistance force of a Kobben class submarine}

The Kobben class (also known as Type 207) is a customized version of the German Type 205 submarine. Fifteen vessels of this class were built for use by the Royal Norwegian Navy in the 1960s. The class later saw service with Denmark and Poland. The boats have since been withdrawn from service in the Norwegian and Danish Navy [9]. The project 207 ships are one-and-a-half hull constructions. The diameter of the strong hull is $4.686 \mathrm{~m}$ and its length is $32 \mathrm{~m}$. The ship is characterized by basic technical data [10]:

$\begin{array}{lll}\text { Total length } & \mathrm{L} & =47.24 \mathrm{~m} \\ \text { Total height } & \mathrm{H} & =8.88 \mathrm{~m} \\ \text { Displacement, surfaced } & \mathrm{D}_{\text {sur }} & =520 \mathrm{t} \\ \text { Displacement, submerged } & \mathrm{D}_{\text {sub }} & =572 \mathrm{t} \\ \text { Test depth } & \mathrm{T}_{\text {depth }} & =225 \mathrm{~m} \\ \text { Maximum speed } & \mathrm{v}_{\max } & =12.5 \mathrm{kt}\end{array}$

During the underwater operation, a number of measurements were carried out to determine the resistance force of the submarine. The measurements were conducted at a depth of $40 \mathrm{~m}$ in the Baltic Sea region, whose salinity was $6 \%$. During operational sailing, the shaft speed was changed from 40 to $110 \mathrm{rpm}$. The change in rotational speed affects the ship's speed; therefore, the mentioned rotational speed corresponds to the sailing speed in the range from 0 to $7 \mathrm{kt}$ $(0-3.6 \mathrm{~m} / \mathrm{s})$. In addition, the maximum speed of the ship at full engine power $(1100 \mathrm{~kW})$ is 12.5 $\mathrm{kt}(6.4 \mathrm{~m} / \mathrm{s})$, which was also taken into account when determining the characteristics of the ship's resistance force.

In order to determine the power generated by the propeller, the current, voltage and sailing speed were measured. Next, using the Kirchhoff's second law, the currents from the battery were added, and the indications from the ammeters measuring the current on the motor were averaged. Then using the technical method of power measurement, the engine power was calculated by means of formula [11]:

$$
P=U I
$$

where: $P-\mathrm{DC}$ power, $\mathrm{W}$;

$U-\mathrm{DC}$ voltage value, $\mathrm{V}$;

$I-\mathrm{DC}$ current value, A.

The use of a technical method of measuring the power of electric motors makes it easy to determine the resistance force characteristics compared to internal combustion engines. The power generated by internal combustion engines is usually determined with indirect methods and is difficult for ready-made propulsion systems. In the case of a submarine, the power generated by the engine takes into account all losses, which allows determining the final resistance force of the ship.

The collected data allowed calculating the power generated by the propulsion system at a given sailing speed and were presented in the Table 1 and Figure 4.

\section{Maneuverability of submarines}

Maneuverability of submarines is defined as the ability to move at a fixed speed at a certain minimum power of main engines. When the ship is not moving, the impact of water is reduced to buoyancy balanced by weight. During the movement between the water and the submerged part of the hull, there are additional water resistance forces. The water resistance force will act in the opposite direction of the ship's movement. In

Table 1. Submarine power measurement results

\begin{tabular}{|c|c|c|c|c|}
\hline \multirow{3}{*}{ No. } & $v$ & $v$ & $P$ & $R$ \\
\cline { 2 - 3 } & $\mathrm{kt}$ & $\mathrm{m} / \mathrm{s}$ & \multirow{2}{*}{$\mathrm{kW}$} & $\mathrm{N}$ \\
\cline { 2 - 3 } & \multicolumn{2}{|c|}{$1 \mathrm{kt}=0.514 \mathrm{~m} / \mathrm{s}$} & & $P / v$ \\
\hline 1 & 0.00 & 0.000 & 0.000 & 0.0 \\
\hline 2 & 2.01 & 1.034 & 8.685 & 8395.5 \\
\hline 3 & 3.07 & 1.580 & 23.040 & 14582.0 \\
\hline 4 & 3.73 & 1.917 & 44.160 & 23034.3 \\
\hline 5 & 4.06 & 2.090 & 56.345 & 26965.1 \\
\hline 6 & 4.45 & 2.290 & 67.130 & 29310.9 \\
\hline 7 & 5.38 & 2.769 & 134.900 & 48719.5 \\
\hline 8 & 7.00 & 3.603 & 246.070 & 68302.0 \\
\hline 9 & 12.50 & 6.433 & 1100.000 & 170993.3 \\
\hline
\end{tabular}


order to overcome the forces of water resistance force and maintain movement, a force acting in the direction of movement and equal to the force of water resistance force is necessary. The source of this force comes from the main engines of the ship. In addition, a ship with good marine properties should be maneuverable and controllable. Maneuverability is the ability to change the direction of movement. This feature determines the ship's maneuvering properties. Underwater, maneuverability is divided into: horizontal and vertical. The steering ability is the ship's ability to stay on a set course in all weather conditions. Lack of maneuverability, manifested in the spontaneous deviation of the ship from a given course causes an increase in drag due to the deflection of the rudder, a decrease in the average speed and increase in fuel consumption [12-15].

The submarine, as a unit moving both in the horizontal and vertical plane, also uses depth rudders. Rudders are divided into: bow and stern depth rudders. The operating conditions of the stern rudders differ from the operating conditions of the bow rudders. The stern depth rudders work directly in the water jets repelled by the propeller, which changes the flow velocity values and affects their efficiency. In addition, the stern rudders are located at a considerable distance from the ship's center of gravity, which means that their use directly affects the change of trim. The bow rudders are located as close to the center of gravity as possible, which means that their use changes the depth (without changing the trim). Additionally, the ship's hull is a hydrodynamic profile and, depending on the speed of sailing, a lift is generated on it. The submarine, by increasing its speed on an even keel, will start to ascend, while a decrease in speed may result in increasing depth.

The art of underwater sailing is based on the skilful use of the ship's speed, bow and stern rudder, direction rudder and proper balancing of the ship to reduce the residual buoyancy. By operating the rudders parallel or opposite, the submarine can change depth in four variants:

- Immerse on an even keel

- Immerse with trim

- Ascent on an even keel

- Emerging with trim

In addition, the ship can move at a given depth on an even keel or with trim, in the event of some failure or inability to balance the ship $[12,16,17]$.

\section{Rudder construction}

The perpendicular (classic) construction of rudders is one of the most commonly used construction solutions. This is mainly due to the fact that this type of rudder is symmetrical, and the horizontal and vertical rudder have approximate surfaces. However, there is ongoing research to improve the efficiency of maneuvering and operation of submarine rudders. The $\mathrm{X}$-type rudders are another solution. The rudder system and axes are angled to the symmetry plane of the submarine (the angle is usually $45^{\circ}$ ). In comparison with the perpendicular rudder, the X-type rudder has the following advantages. First of all, it has a higher efficiency, and its area is less about $10 \%$ than the perpendicular rudder. Secondly, the X-shaped rudders reduce the consequences of their blocking under the water surface, which improves the operational safety. In addition, the X-shaped rudder reduces the heeling moment, weight and the phenomenon of the stern "dipping" during changing the course of the submarine, which allows increasing the stability. The X-type rudder has lesser effect on the propeller operation, which reduces the generated noise [18]. On the basis of the above considerations, the concept of modernization of the rudder of the project 207 submarine with the use of type X was tested. A model of the present and modified unit was prepared, which is shown in Figure 1.

\section{Impact of depth rudder reliability on submarine operational safety}

Depth rudders, as one of the most important components of the ship's structure, have a direct impact on the safety of underwater sailing. During operations, the rudders may be blocked (become stuck) due to deep-sea bombs or malfunctions. In the event of failure of bow depth rudders, it can be counteracted by the stern rudder. If there will be a damage of the stern rudders, steering the ship is significantly more difficult. In such a case, the ship should be balanced for a given angle of stuck rudders and the depth should be maintained only by bow rudders. If the situation allows it, a submarine should go only at the speed for which she was balanced before rudders got stuck. If the bow and stern rudders are stuck, the submarine should be surfaced or laid on the bottom for repair [16].

The description above indicates the essence of safety related to the proper operation of the 


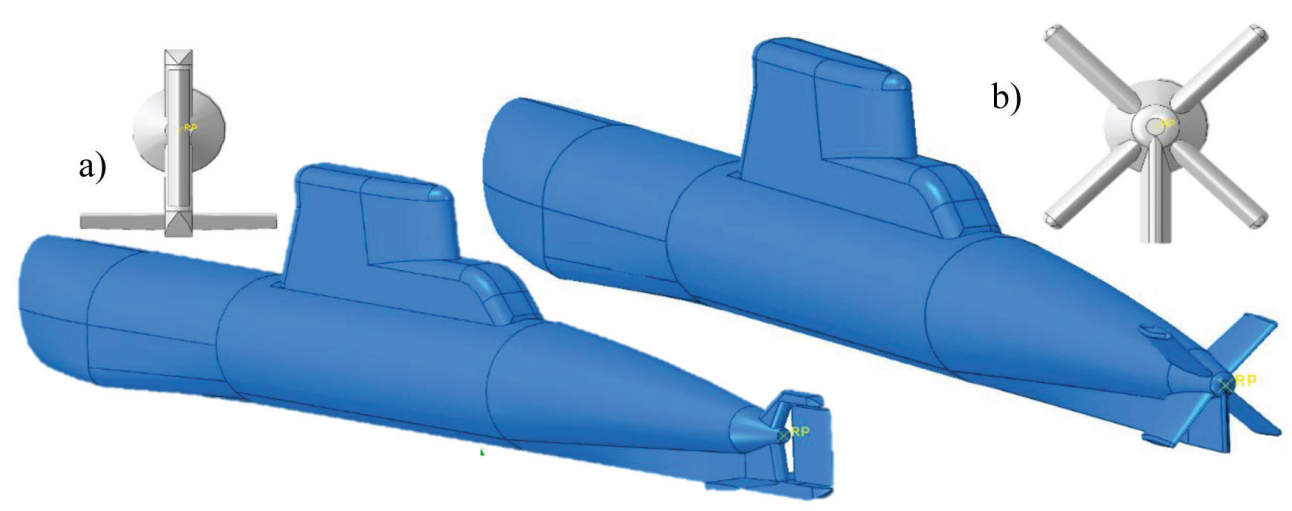

Fig. 1. Models used to calculate the resistance force characteristics a) perpendicular b) X - type

rudders. For example, on September 10, 1955, the Soviet "B-5" submarine damaged the electric propulsion of the stern rudder which was blocked in the $12^{\circ}$ position ascent. The emerging ship hit the destroyer above twice [16]. The rudder of type $\mathrm{X}$ is less susceptible to blocking than the rudder in the classic arrangement [18]; moreover, if one pair of rudders is stuck, there is still a possibility to work with the other pair, which increases the operational safety of underwater sailing.

\section{Determination of resistance force characteristics using the finite elements method}

One of the basic equations of hydrodynamics of ideal fluids describing flow is the Bernoulli equation, which can be expressed in the form [4]:

$$
\rho g h+\frac{\rho v^{2}}{2}+p=\text { const }
$$

Comparing the equation above to the equation for resistance force of the ship (1), it can be seen that the second part of both equations are the same. This is called dynamic pressure. The identity of these expressions makes it possible to use the computer methods describing CFD to determine the approximate ship's resistance force characteristics.

Modern engineering programs allow combining the flow simulations with a strength analysis. It is possible to model the interaction of the fluid on a solid structures in the so-called combined simulations. Such calculations are usually used to determine the strength of pipes or pressure tanks, but in appropriate terms, they can be used to determine the required power of a ship's engine room, at the design stage.

\section{Simulation preparation}

The first stage of the task was to reflect the geometry of the Kobben class submarine. The geometry was recreated on the basis of technical documentation in the CAD program, which was exported to the CAE program. The CAE programs usually calculate a matrix similar to the one described in $[19,20]$. Then, the geometry was prepared for the flow calculations (Fig. 2). The simulation was carried out for the flow velocity in the range of $0-6.4 \mathrm{~m} / \mathrm{s}(0-12,4 \mathrm{kt})$. The submarine was modeled as a rigid body. Due to the fact that the model of the ship is a homogeneous mass, the density had to be selected in such a way that the mass of the model corresponded to the displacement of the submarine. Because a model is a rigid body, all degrees of freedom were assigned in the place where the propeller should be located, which allowed determination of the response (determination of resistance force characteristics) of the whole hull at one point only.

\section{Simulation results}

After correct modeling of the task, a CFD/Standard $[21,22]$ combined analysis was performed. In the first time step, the calculation results in a large reaction spike at zero speed. It is probably caused by the inertia of the whole model and the imperfections of the developed method. The value of the "inertia component" was subtracted from the results and neglected in further analysis. The contact forces caused by the water flow affect a particular FEM element. The sum of all contact forces creates a reaction force at the place, where the model boundary conditions are assigned. This reaction force is the resistance force of the entire ship. The boundary assignment point and the values of contact forces are presented in Figure 3. 


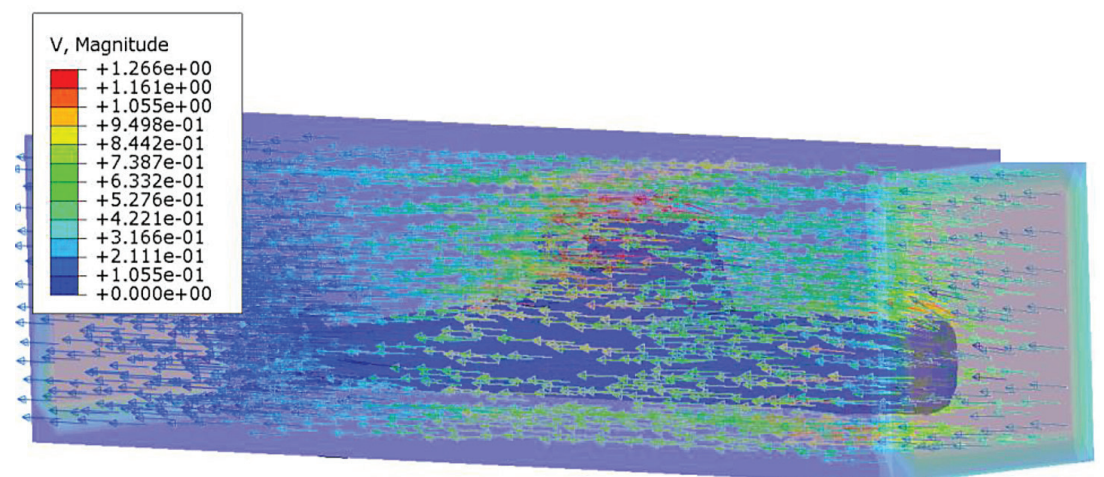

Fig. 2. Water velocity distribution around the ship's hull for a cruising speed equal to $v=1 \mathrm{~m} / \mathrm{s}$

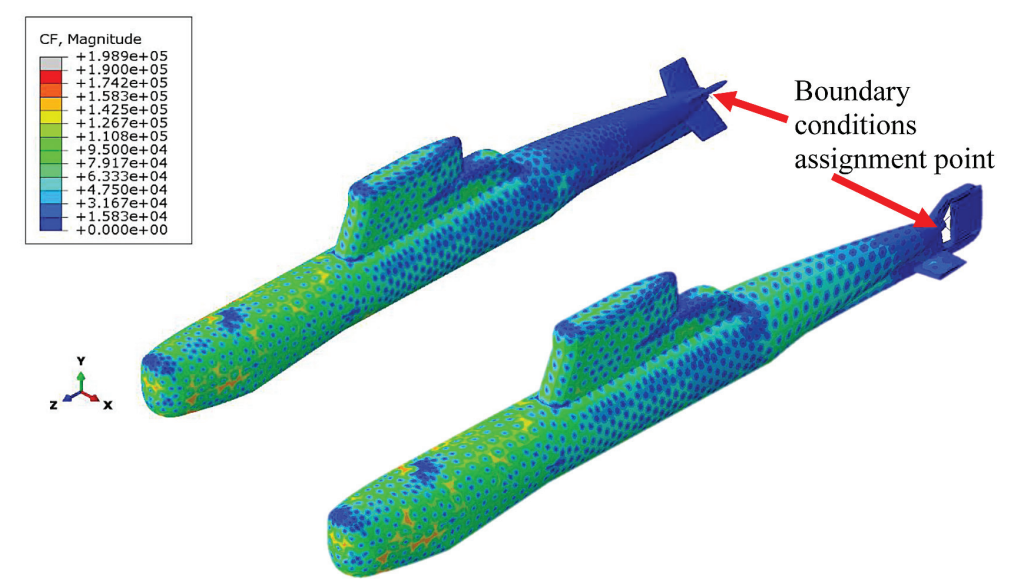

Fig. 3. Values of contact forces on the ship's hull before and after the modernization of the stern steering system

In Figure 4 it is difficult to notice the changes resulting from the modification of the ship's stern. Therefore, Figure 5 shows the percentage differences between the response values before and after modification, as a function of sailing speed.

The presented graph shows that for the value of $0.6-1.5 \mathrm{~m} / \mathrm{s}$ a significant increase in the drag force can be observed when using $\mathrm{X}$ - type rudders; however, in the rest of the sailing speed range, the reaction force decreases by up to $2 \%$ and this tendency persists for higher cruising speeds.

\section{Engine room calculations}

In order to calculate the required towing power, the resistance force should be multiplied by the distance the submarine travels in one second using the formula (2). The power generated on the shaft is not fully converted into useful work. Losses are taken into account by the efficiency of the shaft line efficiency $\eta_{\text {shaft }}$ and propeller $\eta_{\text {propeller }}$. According to the literature $[5,12]$ the propeller efficiency is within the range of $\eta_{\text {propeller }}=0.5-0.65$, while the shaft line $\eta_{\text {shaft }}=0.97-0.98$. The power of the machines that is needed to overcome the water resistance force is calculated from the formula:

$$
P_{e}=\eta_{\text {shaft }} \cdot \eta_{\text {propeller }} \cdot R \cdot v
$$

Knowing the values from the measurements, the coefficient of efficiency of the entire hull can be determined. The efficiency of a submarine results from the efficiency of the propulsion system and the roughness of the hull and the resistance force of the protruding parts, using the expression:

$$
\frac{P_{\text {measured }}}{P_{\text {calculated }}} \approx \eta_{\text {submarine }}=0,633
$$

The use of the efficiency coefficient of the entire ship can be used for the comparison of the calculation results with the measurement results, which allows authenticating the simulation calculations.

According to [23] transportation, as one of the branches of national economy with destructive impact on the natural environment, stays in the main area of interest of sustainable development. 


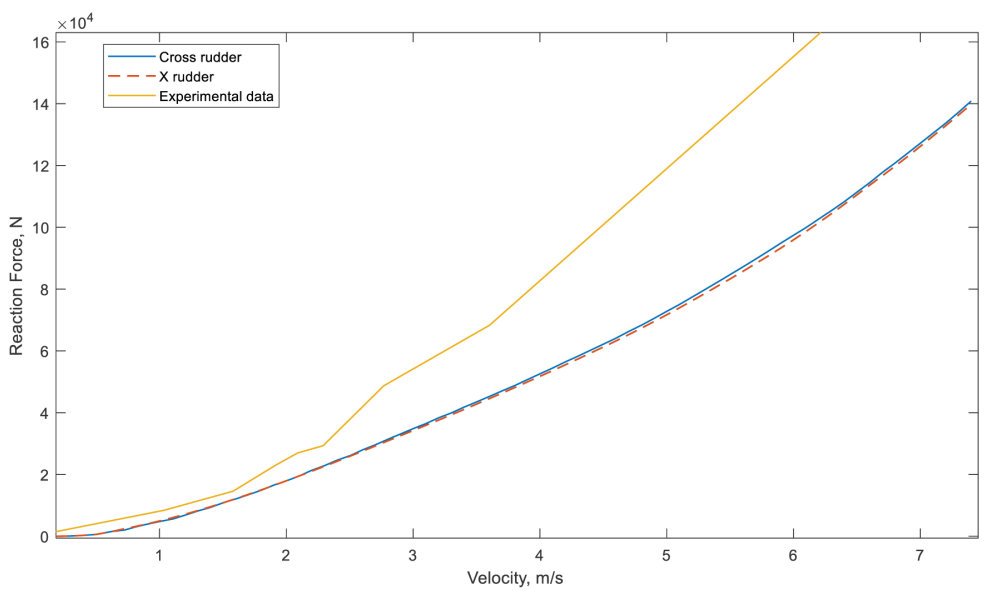

Fig. 4. Summary of the calculated resistance force and measured characteristic

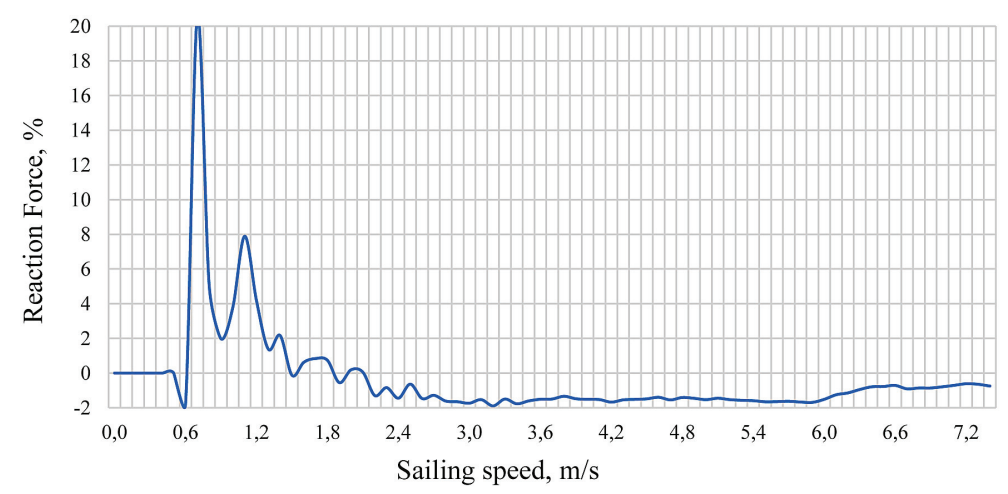

Fig. 5. Percentage differences between before and after modification values as a function of sailing speed

Consequently, this led to the idea of sustainable transport. Despite many negative impacts of transport on the environment (air pollution, climate change, noise, congestion, accidents, etc.) it is also one of the main factors of the economic development. Therefore, the effective use of resources of transport system must be sought, while minimizing the negative impact of transport on the environment. The use of the presented methodology will reduce the costs and increase the operational safety of designed marine vehicles, making them more sustainable.

On the basis of the calculations, it was found that the power of the engine room could be reduced by about $8 \mathrm{~kW}$ with the modification of the rudder. This reduces the electric power requirement from batteries. With prolonged sailing, the saved energy allows a ship to stay longer under

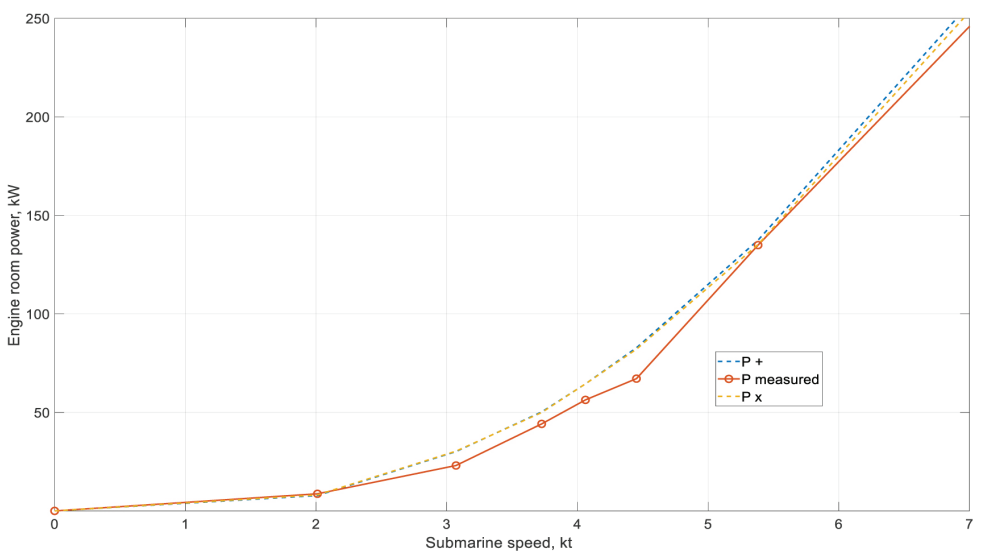

Fig. 6. Comparison of power curves after taking into account the efficiency of the entire ship 
the water surface, while maintaining the full functionality of the devices responsible for the ships operational safety.

The X-type rudder (Fig. 1) allows reducing the ship's resistance force by $2 \%$ for a range of sailing speeds from 1.8 to $6.4 \mathrm{~m} / \mathrm{s}$. Increasing the resistance force value to $20 \%$ for the $\mathrm{X}$ rudder system for initial speeds (up to $1.8 \mathrm{~m} / \mathrm{s}$ ) may result from the inaccuracy of the calculation model or other non-linearity of the phenomenon (Fig. 6). The results of the simulation should be verified by model tests, in particular for low sailing speeds (up to $1.8 \mathrm{~m} / \mathrm{s}$ ).

\section{CONCLUSIONS}

The technical measurement of the engine power of ships with electric diesel drive makes it easy to determine the resistance force as a function of sailing speed. Using the basic laws of electrical engineering, the power necessary to power the main electric motor on the submarine was determined. Determining the electric power of the engine is much easier compared to the power of internal combustion engines, in which indirect methods should be used. The obtained characteristics allowed the comparison of the simulation results with reality, which helped refine the presented method.

The use of combined FEM and CFD simulations allows determining the initial ship's resistance force characteristics. Appropriate innovative task preparation reflects the nature of the resistance force curve. It can be seen that the nature of the reaction force as a function of the ship's speed is consistent with the theoretical assumptions; however, it differs from the measured values. The determined value of the ship's efficiency is within the scope described in the literature; therefore, the described methodology can be used in further research on the ship's resistance force. The measured values are increased because it takes into account the efficiency of the propeller, bearings or shaft line. In addition, it takes into account the hull roughness coefficient and the efficiency of the entire propulsion system.

Reducing the resistance force value directly affects the operational capabilities and operational safety of the ship. Lower resistance forces reduce the use of energy reserves, which allows increasing the range and the submarine ability to stay submerged (increasing autonomy). In addition, the reduction in fuel consumption is more ecological, which allows the use of sustainable transport.

A modification of rudders could increase the ship's maritime prowess and also increase the operational capabilities of a submarine. In addition, the method used to determine the resistance force curve makes it possible to check the impact of each type hull modification. It allows designers to check the validity of their ideas without having to incur significant costs.

\section{REFERENCES}

1. Chen, C.; Lin, T.-Y.; Chen, B.-Y.; Kouh, J.-S. Parametric design and optimization of a pivoting S-Type rudder for containerships.; 2018.

2. Kim, J.-H.; Choi, J.-E.; Choi, B.-J.; Chung, S.-H.; Seo, H.-W. Development of energy-saving devices for a full slow-speed ship through improving propulsion performance. International Journal of Naval Architecture and Ocean Engineering 2015, 7, 390-398, doi:10.1515/ijnaoe-2015-0027.

3. Park, S.; Oh, G.; Hyung Rhee, S.; Koo, B.-Y.; Lee, H. Full scale wake prediction of an energy saving device by using computational fluid dynamics. Ocean Engineering 2015, 101, 254-263, doi:10.1016/j.oceaneng.2015.04.005.

4. Marine Propellers and Propulsion; Elsevier, 2012; ISBN 978-0-08-097123-0.

5. Charchalis A. Opory okrętów wojennych i pędniki okrętowe (Resistance force of warships and ship propellers - in Polish); Akademia Marynarki Wojennej im. Bohaterów Westerplatte: Gdynia, 2001;

6. Terziev, M.; Tezdogan, T.; Oguz, E.; Gourlay, T.; Demirel, Y.K.; Incecik, A. Numerical investigation of the behaviour and performance of ships advancing through restricted shallow waters. Journal of Fluids and Structures 2018, 76, 185-215, doi:10.1016/j.jfluidstructs.2017.10.003.

7. Mironiuk, W. Model-based investigations on dynamic ship heels in relation to maritime transport safety. Archives of Transport 2015, Vol. 33, iss. 1.

8. Jarosz A. Ship Model Pools; Wydawnictwo Morskie: Gdańsk, 1977;

9. Poland, Germany to Form Joint Submarine Command Available online: https://www.executivegov. com/2016/06/poland-germany-to-form-joint-submarine-command/ (accessed on May 31, 2020).

10. Gołąbek I., Sobociński W. Opis techniczny okrętu podwodnego typu Kobben (Technical description of the Kobben class submarine - in Polish); Dywizjon Okrętów Podwodnych: Gdynia, 2003; 
11. Bolkowski S. Elektrotechnika, Podręcznik (Electrotechnics, Coursebook (in Polish). Wydawinctwo Szkolne i Pedagogiczne, 2019.

12. Teoria okrętów podwodnych [Submarine Theory - in Polish]; Polish DoD: Gdynia, 1965;

13. Park, J.-Y.; Kim, N. Design of a safety operational envelope protection system for a submarine. Ocean Engineering 2018, 148, 602-611, doi:10.1016/j. oceaneng.2017.11.016.

14. Pan, Y.; Zhang, H.; Zhou, Q. Numerical prediction of submarine hydrodynamic coefficients using CFD simulation. Journal of Hydrodynamics, Ser. B 2012, 24, 840-847, doi:10.1016/ S1001-6058(11)60311-9.

15. Krata, P.; Montewka, J. Assessment of a critical area for a give-way ship in a collision encounter. Archives of Transport 2015, 34(2).

16. Kierowanie okrętami podwodnymi [Commanding of Submarines - in Polish]; Polish DoD, 1965;

17. Kiciński R. Okręt podwodny i jego stery. Przegląd Sił Zbrojnych 2020.

18. The Effect Analysis of Rudder between X-Form and Cross-Form. In: Proceedings of the 2017 3rd
International Conference on Computational Systems and Communications (ICCSC 2017); Clausius Scientific Press Inc., 2017.

19. Lozia, Z.; Kardas-Cinal, E. The use of a linear half-vehicle model for the optimization of damping in the passive suspension system of a railway car. Archives of Transport 2016, 39(3), doi:10.5604/08669546.1225448.

20. Szturomski, B. Inżynierskie zastosowanie MES w problemach mechaniki ciała stałego na przykładzie programu ABAQUS [Engineering application of FEM in problems of solid mechanics on the example of the ABAQUS program - available in Polish]; Wydawnictwo Akademickie AMW: Gdynia, 2013;

21. Abaqus 6.14 Theory Manual; Simulia, Dassault Systems, 2014;

22. Kohnke, P. Ansys Theory Reference, Relase 5.6 1999.

23. Jacyna, M.; Wasiak, M.; Lewczuk, K.; Kłodawski, M. Simulation model of transport system of Poland as a tool for developing sustainable transport. Archives of Transport 2014, 31(3), doi:10.5604/08669546.1146982. 